\title{
The Social Construction of Ageing through Work: Economic Structure and Life-world*
}

\author{
MARTIN KOHLI, JOACHIM ROSENOW and \\ JURGEN WOLF†
}

\section{ABSTRACT}

The analysis of modern-age stratification systems must be based on the social organisation of work. This requires a theoretical approach that takes into account the structure of economic production, but also the fact that work is a meaningful activity of human beings within their life-world. The task therefore consists of integrating 'materialist' and 'interpretive' approaches to social reality. This integration is attempted in an examination of the special problems encountered by workers in the second half of their work life, as created by the 'construction of ageing ' in the industrial firm. Existing approaches drawn from industrial sociology, stress structural features of the production process, whilst labelling theory stresses culturally induced age labels. Both are one-sided. A more comprehensive approach has to conceptualise the industrial firm as an actor with strategies based on economic rationality and as a life-world constituted by what is taken for granted by its members. The final section applies this framework to an empirical case study.

\section{General theoretical considerations}

\section{Purpose and scope}

This paper is a contribution to the analysis of ageing and the life-course as part of social structure. We focus on how the economic system deals with age and ageing, and at the same time contributes to the construction

* Revised text of a paper presented to the roth World Congress of Sociology (Research Committee on Ageing) August 1982, Mexico City.

$\dagger$ Freie Universität Berlin, Institut für Soziologie, Garystr. 21, 1000 Berlin 33, W. Germany. 
of the age stratification system. The theory of age stratification ${ }^{1}$ has, so far, remained essentially formal. There have been no attempts in this framework to study, for example, the origin and change of the retirement limit, and thus to explain the given age stratification in terms of broader social processes.

In our opinion, such an explanation must concentrate on the social organisation of work. This requires some theoretical effort. We share the view ${ }^{2}$ that research on ageing has become isolated from mainstream theorizing in sociology, and therefore theoretically unproductive. For our purpose, we need to consider the basic structural features of the economic process. However, this is not enough; how these features shape work careers, and create special risks for older workers, must be analysed on the microsociological level, too, i.e. by considering the structures of the life-world.

With reference to this broad task, our aim is more modest. We are not able to propose a well-integrated theory; rather, we propose some theoretical elements from which such a theory might be constructed at a more advanced stage. We discuss but one portion of the life-course, i.e. the second half of the work life $^{3}$ and we present but one empirical case, namely, the development of a firm-specific new retirement scheme. Before turning to these more limited examples, however, some remarks on their place in, and relevance for our more general concerns are in order.

\section{Work and ageing}

(a) Historically, not only the chronological age at which the socially structured transitions in the life-course occur has changed, but the character of the temporal organization itself. In the development over the last four centuries, the broad picture has been one of increasing 'chronologisation', i.e. of a growing relevance of chronological age as a criterion for membership in different social positions, and thus for the differentiation of life stages and of career sequences. Old age itself has become more clearly distinguished as a specific stage of life, and delimited chronologically, with the result of a sharp tripartite division of the life-course into a phase of preparation, one of economic activity, and one of retirement. ${ }^{4}$ (This does not apply to women as generally as to men; however, housewives are exposed to this division by way of their husbands.) As socialisation (in the sense of social engagement) is to a large extent effected by participation in work, the third phase has become a phase of social disengagement.

The chronologisation has occurred in the transition from a household- 
based economy (farming and artisanry) to an entrepreneurial economy based on salaried labour recruited from labour markets. Processes during this transition that can be interpreted as elements of the overall chronologisation process include, for example, the development of an age-graded school system, of other age-graded systems of public rights and duties, the transformation from a demographic pattern of random experience to a pattern of a predictable life-span, and the narrowing of the spread of age for the 'normative' events of the family cycle and work career.

Of special interest to gerontology is retirement. The phase of old age is socially defined by the transition from salaried work to retirement. While this seems a self-evident fact today, historical research has shown it to be a rather new development. In the pre-industrial economy there existed some forms of retirement (e.g., the older farmer moving to an outhouse after passing control over the property to his heir), but their prevalence was low, and they were not dependent on a specified chronological age. The development of nationwide pension systems occurred rather late in the industrialisation process, and only gradually resulted in the setting of a generalised retirement limit.

(b) Today, in Germany, the retirement limit is again a topic of much debate. The real age of retirement has dropped substantially during the last decade (the labour market participation of men aged $60-64$ has dropped from $76 \%$ in 1968 to $44 \%$ in $198 \mathrm{I}$ ). This is partly the result of the introduction of a 'flexible retirement limit' of $6_{3}-6_{5}$ for men (supplanting the fixed limit of $6_{5}$ ), which had the immediate effect that the vast majority of men retired at 63 , and partly of the provision that unemployed workers after one year of unemployment can retire at $60-a$ provision which was exploited systematically by many firms to pension off their 59-year-olds ("Aktion 59'). The main factor behind this development, as well as behind the actual debate, is the pressure of the labour market.

With the present rate of unemployment, the necessity for shortening the working life is - however reluctantly - broadly accepted. The issue is how this shortening should occur: whether by shortening the daily (or weekly, or yearly) work hours, or by lowering the retirement age (and raising the number of years spent in the school system). This issue has far-reaching effects on social structure.

(c) Within the period of participation in the labour force there seem, on first sight, to be few age-relevant processes. Adult work life up to retirement is not punctuated by any 'normative' (i.e. socially regulated and highly prevalent) life events. It can be shown, nevertheless, that there is enough social regularity to warrant speaking of the 'social 
organisation' of ageing through work, mainly on the level of the economic enterprise. The individual enterprise in its policy of personnel recruitment and allocation treats the basic features of the retirement regime as given; therefore, the level of the enterprise seems to have nothing to contribute to an analysis of the retirement and age stratification problem at the macrosocial level. This is not correct, however, as we shall argue later in connection with our case study.

(d) Finally, there is the level of the biography of the individual actor. This level is included in our empirical work, ${ }^{\mathbf{5}}$ but will not be treated in detail in this paper. Here, too, a theoretical orientation to economicstructural conditions is indispensable. The work biography cannot be adequately conceptualised as a mere fulfilling of ' work role obligations', as coping with life events, surfacing in the area of work, or as trying to solve developmental tasks. Instead, one has to take account of salaried work being the means to gain a living, and of the resulting necessity of maintaining one's work capacity over the whole work life while trying to maximise its returns. This is is not to say that all workers empirically are oriented towards maintaining their work capacity, or maximising their salary. It is, however, a core structural dimension of their career.

\section{Economic structure and life-world}

The impact of the organisation of work on age stratification and ageing, as discussed so far, points to the need for theories of economic structure. Formal theories of system properties, or of role structures are not powerful enough. An appropriate theory must be 'materialistic' in the sense that it takes account of the structural features of economic activity in the given system of production, for example patterns of action that derive from the economic rationality of privately owned competitive enterprises. On the other hand, such an approach reveals itself to have limited power, too. It does not account for the action and communication dimension of social reality; attempts to 'derive' these dimensions from economic-structural properties - as in (orthodox) Marxismquickly reach their limits. This points to the need for theories of the life-world; the life-world is the basic level of the constitution of social reality. Reality is constituted by what is taken for granted by the members, i.e. by their meaning structures. Economic-structural conditions are relevant in the context of these meaning structures. They are not, however, a contingent mass of features that become meaningful only by individual action, or definition of the situation. Although produced by human activity, they are given to the members as a reality 
that is taken for granted and thus have the quality of 'natural' lawfulness.

So what is required is a theory that treats economic structures as part of the life-world. It is not a question of economy versus life-world, but rather of how economic-structural properties become relevant properties of the life-world. Evidently, this a very difficult theoretical problem and we see our merit more in posing it than in proposing a solution. We are encouraged by the fact that in German sociology this is currently (again) a hotly debated topic; both the materialist (or system) and the interpretive theorists seem to be willing to reach out over and across the boundaries of their preferred paradigm. ${ }^{6}$

In the following sections on the organisation of work in industrial enterprises we shall show in more detail the inadequacy of one-sided approaches restricted to either economic-structural or life-world reality.

\section{Theoretical approaches to the construction of ageing in the industrial firm}

\section{The approaches of labelling theory and industrial sociology}

Ageing in the firm is a process of social construction resulting in a specific age stratification, and in age-specific risks for the employees. Two approaches to explaining this process currently exist, the labelling approach and the approach of industrial sociology.

Following the distinction between economic-structural and life-world reality, we shall show that each of these approaches is one-sided, and therefore inappropriate. We shall then go on to present a more comprehensive approach. Our argument is based on our empirical study of ageing processes in the firm (cf. section 3 ).

The labelling approach (a concept originally developed in the sociology of deviance) considers the treatment of older employees by the firm to be the result of a process in which they are attached a 'label', i.e. seen in terms of age-limited performance evaluations that are part of the taken-for-granted meaning structures. This process is used to explain why the older employees are subject to increasingly negative performance evaluations from the personnel management quite independent of their true performance capacities.

This argument is based mainly on psycho-gerontological findings according to which chronological age is not the decisive variable for explaining the performance capacity in the second half of the working life. The performance capacity is instead seen to result from a number of other factors which are considered to be independent of each other. 
They include, among others, the exercise of skills, environmental stimulations, performance attitude, aspirations, health, social and economic status, and previous work experience. ${ }^{7}$ According to this theoretical model, specific performance problems of older employees are mainly the result of a lack of correspondence between the individual performance profile - determined by unique biographical factors - on the one hand, and the job requirements on the other. ${ }^{8}$ The fact that older employees are generally subject to higher risks, and subsequent problems, is attributed to the societal prejudices against old age. ${ }^{9}$

Within this concept, the firm is seen merely as a field of application of generalised life-world norms, not as an actor with specific economic rationales. In our view, this argument is untenable for three reasons.

First of all, there is as yet no convincing empirical evidence supporting the labelling hypothesis. Recent studies have shown that older employees are not generally considered to have a diminished performance capacity. ${ }^{10}$ Our own empirical study of the deployment of personnel in the firm points to the same direction. We have found that the personnel management does not practise generalised typifications of performance according to chronological age, but rather assesses performance individually and evaluates it in the specific context of the firm and the job requirements involved. ${ }^{11}$

Theoretically speaking, it seems unlikely that the firm would suspend the profitable utilisation of its resources by deploying its personnel primarily on the basis of objectively inappropriate age-specific performance labels.

And finally we will show that the personnel deployment system in the firm and its age-specific effects cannot be explained on the criterion of performance capacity alone. Quite independently of the performance capacity, chronological age is an important selective criterion for the labour deployment in the firm.

In contrast to this normative (life-world) concept, the approach of industrial sociology explains the age-specific risks essentially with economicstructural causes. According to this approach, ${ }^{12}$ the economic pressure to maximise profits which dominates the actions of privately owned competitive firms leads, by intensification of work, to the risk of diminished performance capacity with the duration of employment. Through recruitment and allocation according to performance, the older employees are steadily pushed into marginal positions in the firm or even dismissed altogether. At the same time, this age-selective strategy drastically lowers the re-employment chances for laid-off older employees.

This approach holds the firm to be a system of action determined 
purely by economic imperatives. Such a view raises a number of problems.

(I) The firm cannot be defined merely in terms of economic logic. Rather, it simultaneously represents a meaningfully structured life-world of interacting individuals or social groups. This implies that the economic pressures dominating the firm can only be effective in the context of the interpretations and norms of the members.

One essential element of these norms and interpretations is the reciprocity norm. This is the basic concept of justice and equity under which individuals organise their social actions, ${ }^{13}$ and as such one of the key features of what they take for granted. Under the conditions of salaried work, it is defined in two temporal dimensions. In everyday time, it refers to the employees' assumptions of a fair correlation between their actual work performance and the pay or gratifications by the firm. However, the employees must ensure their reproduction not just for the moment but also for the whole duration of their dependent employment; hence the reciprocity norm also extends to the lifetime perspective. On the one hand, this involves the expectation that the utilisation of labour in the firm does not endanger the lifetime protection of the capacity for work. On the other hand it is felt that the employees furnish the firm with an investment based on their continuous performance, their willingness to accept responsibility, their reliability, etc. - i.e. especially the non-contractual elements of their work - for which the firm will reward them with special benefits if their performance capacity should diminish some day. It is in the context of this normative orientation and the corresponding interpretation of the situation in the firm that the management must realise its economic imperatives. If the firm follows the economic pressure of maximising performance without regard for the reciprocity norm, this will result in a potential permanent conflict in which the relationships of power become an open issue. This would in turn endanger the realisation of the economic objective itself by resulting in social disintegration, various forms of withdrawing performance (especially concerning the non-contractual elements of work) and negative effects on the employees' performance motivation in general. Thus economic rationality includes guaranteeing the social integration in the firm.

(2) Even under purely economic-structural considerations, the enterprise is not simply a place of direct implementation of the economic imperative of maximising profits. This imperative can only be realised if some measure of independence from the contingencies of the market can be maintained to respond flexibly to the changing conditions of profit making which are beyond control. ${ }^{14}$ The enterprise is thus subject 
to two separate and sometimes conflicting pressures from the economic structure, i.e. maximising profits and securing autonomy, which have to be balanced in the organisation of the production process and the deployment of labour.

\section{Towards a more comprehensive approach}

A more comprehensive approach must spell out the ways in which the firm accounts for the fact that economic efficiency includes the consideration of life-world norms, and integrates the imperatives of maximising profits and maintaining autonomy. The latter results in three guidelines for personnel management: ( 1 ) maximising performance; (2) maximising the length of usefulness of labour; and (3) maintaining continuity.

(I) As far as maximising performance is concerned, the firm tends towards a maximum exploitation of the performance resources of the workforce. This is largely based on the performance capacities of younger workers. Although this performance standard is tempered somewhat by the consideration of the lifetime reciprocity concepts, it still raises the risk for the employees of being transferred and downgraded in the second half of their working life ${ }^{15}$ because high performance requirements tend to diminish the performance capacity, based either on the 'natural' exhaustion or obsolescence of performance resources, or on long years of high (or one-sided) stress. This reduction of the time of usefulness may also influence the firm's autonomy requirements and thus the dependence on external labour markets. In addition, it prevents the full utilisation of the social and firm-specific skills acquired in the long period of socialisation in the firm.

(2) In order to avoid these effects and protect its autonomy, the firm must take into account the length of usefulness of labour. In this respect, there are age-specific effects concerning four areas of personnel deployment: exploitation of performance; recruitment of personnel; allocation of personnel; and reduction of the workforce.

In the area of exploiting performance, maximising the length of usefulness calls for an essentially welfare-oriented, moderate use of the resource of labour, and a policy which commits the employees to the firm, so that the dependence on the external labour market is reduced. This applies at least to those employees whose qualifications cannot, or only at high cost, be replaced with new recruitments from the external labour market.

The selective application of these usefulness considerations is facilitated 
through the segmentation of the internal labour market: the firm recruits an easily replaceable fringe workforce and a core of employees which are difficult to replace. In dealing with the fringe workforce the management can set high performance requirements without any greater concern for the lifetime consequences because any performance deterioration is easily compensated by new recruitments from the external labour market. In the case of those qualifications which cannot be easily replaced from the external labour market, or only at high costs, the management must protect its autonomy by combining appropriate performance requirements with a strategy aimed at prolonging the time of usefulness and the commitment to the firm.

Such a commitment is achieved with a policy of social integration which prevents the open discussion of the question of power in the firm and fulfils the reciprocity expectations of the employees. In the chronological context of the work biography, the firm can allow for these reciprocity concepts by interpreting the performance of the employees as investments which are not immediately rewarded but honoured with status improvements in the course of the working life. Hence, if the investment pays off only with the length of employment in the firm, remaining in the firm becomes a motivating rationale.

As far as the recruitment of personnel from the external labour market is concerned, the orientation to the length of usefulness leads to grading the chances for employment. The shorter the remaining period of usefulness, the smaller the autonomy gain and the profitability of the investment in human capital for the firm. As a result, the employment chances of the employees decrease with age. This discrimination against older employees is analytically quite independent of their true, or projected, performance capacities.

The orientation to the length of usefulness also leads to age-specific effects in personnel allocation. Largely independent of the actual performance capacity of the employees, it tends to contribute to the shifting of the risks of status or job loss to those employees whose usefulness for the firm is either doubtful or restricted. The usefulness period is doubtful in the case of young employees who possess enough mobility to avoid obstacles. Restricted usefulness periods are typical for older employees who are approaching the end of their work biography: their downgrading or even dismissal involves little negative effect on the period of usefulness and hence on the autonomy of the firm. This age-space logic is especially effective when jobs ' with a future' are concerned. These jobs are usually filled first with 'middle-aged' employees and then with younger individuals.

The age-specific allocation of personnel generally does not raise any 
problems for the firm, and our case studies have shown that it largely corresponds with the biographical expectations of the employees themselves. After the period of settling down, of founding a family and of making the necessary purchases is over, the material goals have more or less been reached, and the education of the children is provided for or completed, then the biographical aspirations undergo a certain change. Many of the industrial workers are no longer interested in acquiring better status or better jobs requiring additional efforts. Instead they become primarily interested in protecting their achievements.

There is one difficulty, however: as the firm is forced to protect its autonomy by creating a long-term commitment to the employees, and an internalised motivation for work, its benefits for older workers attain special importance for the process of socialisation in the firm. If the treatment of the older employees clashes with their reciprocity concepts, this sets an example for the younger employees, demonstrating how the firm will some day 'honour' their present performance. This is detrimental to the development of close identification with the firm and of social skills relevant to the firm. In order to avoid these negative effects the firm tends to resort to seniority systems. ${ }^{16}$ These seniority practices are usually established at plant level in a bargaining process with the employees' representatives or unions, leading to informal and formal agreements concerning employment protection and status security for older employees.

As far as personnel reduction is concerned, the orientation to the period of usefulness tends to shift the risk of dismissal to those with restricted or doubtful usefulness, i.e. to the oldest and youngest age groups. But whereas the older employees enjoy the protection of seniority rights, there is no such protection for the younger ones. This concentration of the risks on the younger employees can be justified with considerations of reciprocity, according to which the younger employees have not yet invested much in the enterprise; it is moreover functional under economic-structural considerations in the sense that the younger employees have acquired only limited firm-specific skills relevant to maintaining the autonomy of the firm.

However, this practice merely reduces the special risk for older workers of being eliminated from the internal labour market of the enterprise. Concerning the incorporation of employees from the external labour market, age-specific risks continue to dominate. Under considerations of the leng th of usefulness, it is especially the older employees who are faced with the prospect of being laid off for longer periods of time. This problem does not concern the firm as such: as an external factor it bears little consequence for the legitimatory and socially integrative aspects of the firm's deployment system. Instead, this 
group - along with other socially deprived groups - poses serious legitimatory and integrative problems for the social policy of the state.

(3) The objective of maintaining continuity also serves to protect the autonomy of the firm in terms of minimising the dependence on the external labour market and of making possible the uninterrupted tradition of qualifications and skills. The management must strive to reduce the risks involved in age-specific personnel losses and the necessity of replacing them from the external labour market. That calls for a specific stratification according to age and a corresponding recruitment policy. The workforce must be composed of equal proportions of all (chronological) age groups, while the continuous attrition process in the group of the oldest employees is compensated by new recruitments from the youngest groups.

Such age stratification and age-specific recruitment policy ensure a steady, non-intermittent replacement of personnel. At the same time it provides for the continuous tradition of those qualifications and skills which are not available, or only at high cost, on the external labour market. This includes firm-specific as well as social qualifications, both of which are attained primarily in long years of experience and socialisation processes in the firm and must be passed on in a continuous process of older employees training the younger ones.

In mixed-age groups, the older workers fulfil a direct control function for maintaining a continuous process of production on the basis of their special social qualifications. At the same time, they play an important role in the socialisation process, passing their qualifications on to younger employees. The same applies to firm-specific skills: the knowledge and experience gained in long years of working in the firm, especially in skilled jobs, is an essential prerequisite for implementing the performance expectations of the firm, and it is also passed on to the younger generations in the context of co-operative work organisation.

Ageing thus involves the creation of specific resources for the firm not only in terms of immediate benefits but also in preserving the continuity of firm-based qualifications and skills - an objective which also contributes to the establishment of seniority rules quite independently of reciprocity norms. However, for the oldest employees (empirically, those above the age of 55), the situation is different. They have already fulfilled their function of socialising the younger employees, and of preserving the continuity of skills and knowledge, so that new 'traditionkeepers' have grown up. Their potential period of usefulness is extremely restricted. Hence, particularly under conditions of personnel reduction, the firm is interested in laying them off; and by giving compensation payments ('Sozialplan'), it can do so without losses in legitimation.

With these theoretical considerations we have outlined the basic 
economic-structural and life-world action orientations which the firm must follow if it is to act rationally. How these orientations can be empirically realised by the firm depends on the specific conditions of the consumer market, the labour market, the available technology, etc. Our theoretical outlines are thus to be seen not as a description of empirical reality but as a reconstruction of the general conditions of economic rationality, in other words, of the general action patterns that are functional for maximising economic rationality. It is not possible to state positively that the personnel management is empirically motivated by this goal; what can be shown is that the empirical facts can be interpreted and explained as being a realisation of the functional patterns. (The empirical analysis is thus not an empirical test in the usual sense, but a validation of the theoretical pattern in terms of the logic of functional analysis.)

This is what we propose to do, using a specific case example: we shall demonstrate that the retirement policy of the firm - given its specific conditions - can be accounted for by the general action orientations outlined so far.

\section{An empirical case: flexible retirement as a strategy in industrial work}

\section{The case study}

In a continuing study on 'work and ageing', ${ }^{17}$ we examine two related fields of questions: ( $I$ ) the social organisation of ageing processes in industrial work, i.e. the age-specific aspects of personnel management and the specific problems which arise from this for older employees in the second half of their working life (risks of a drop in performance capacity, status, and qualification); and (2) how these problems are coped with by the employees concerned.

The investigation is a qualitative one, i.e. we do not strive for data distributions, but for detailed structural configurations on the basis of case analyses. The cases are three large-scale enterprises (one in the cigarette industry, one in the metal industry and one in the electrical industry) in West Berlin.

For the first complex of questions we interviewed executives and foremen about the organisation of work. For the second complex we obtained extensive narrative interviews with 54 German male employees - taken from three qualification groups (unskilled/skilled workers, low-level white-collar employees) and from three age groups $\left(35-39,45^{-49}, 55^{-59)}\right.$ - to reconstruct their individual biographies. 
The processes by which the elderly employee has come to his present position and has built up his orientations are analysed with regard to his life-course perspectives, biographical typification and coping style. The following discussion refers to the first complex only, i.e. to the social organisation of ageing processes as a result of firm-specific policies of personnel management. We shall have to restrict ourselves to some key findings. ${ }^{18}$

\section{Retirement schemes and economic interests}

The cigarette enterprise that we investigated practises its own retirement programme, which was negotiated between management and union in 1977 . Since $198 \mathrm{I}$ this regulation (in a slightly modified form) is part of the collective wage and salary agreement for the West German cigarette industry. It provides the following alternatives: older employees may - two years before they reach the earliest possible age for retirement, i.e. at $6 \mathrm{I}$ for men, $5^{8}$ for women and handicapped persons - choose among three alternatives (provided they have been working in the firm for 15 years); it is possible for them to (I) stop working, with the firm paying $75 \%$ of the wage/salary they last received until their retirement age; (2) work only part-time (20 hours per week), but receive their full wage/salary; or (3) go on working as before.

This regulation resulted mainly from an initiative of the management as an alternative to the union's demands. The union's intentions in these negotiations aimed at reducing the employees' strains by adverse working conditions as well as at relieving the labour market, i.e. by reducing unemployment. The effects on the labour market remain unconsidered here. What we are interested in is the fact that this firm-specific regulation meets the gerontologists' demands for a 'sliding' retirement and for an opportunity to choose among different modes of retirement. The regulation also meets the preferences of the great majority of older employees for an earlier retirement age and part-time work, ${ }^{19}$ while offering the formal right to go on working beyond the fixed age. In contrast to the extensively practised efforts of other firms to pension off their older employees ('Aktion 59'), no public funds are debited here. This model is, on the contrary, a very expensive one for the firm.

Because the cigarette industry makes very high profits, additional costs are comparably easy for it to bear, but this is surely not a satisfactory explanation for the implementation of this regulation. The regulation was initiated by management representatives because it was 
more 'economically acceptable'20 than the union's demand for reduction of shift work and longer vacations.

The following is to show that this flexible retirement scheme in the German cigarette industry is the result of the specific economic situation of interest within this industrial branch, given the structural need to mechanise and to organise the manufacturing process so that it can be optimally controlled. For the firm, this regulation produces above all two desired effects: (I) a higher social integration of the workers; and (2) a lowering of the real retirement age (i.e., the age of withdrawal from the firm).

In accordance with our conception of the firm as an 'actor' which wants to ensure its relative autonomy and which, to this purpose, uses labour and technology as manipulable resources to organise the manufacturing process, we have to start with an analysis of this relation. The daily output of the factory is about $72,000,000$ cigarettes, and the production goes to a highly stable consumer market. Sales fluctuations are about io per cent, but calculably related to seasonal conditions. For this reason, the personnel management is not primarily oriented to creating a disposable fringe workforce. Due to market competition, an increase in production costs cannot be immediately passed on to the market, but has to be compensated by increased productivity. Permanent rationalisation with its aims to reduce the necessary working time and to intensify the use of labour (in the sense of working at maximal capacity) results from these conditions.

Accordingly, the level of automation in this firm is very high (except in the stock and dispatch departments). The actual manufacturing process, i.e. the transformation of the material, proceeds in relative independence of manpower. Rather, the jobs within the manufacturing process are of accompanying or compensatory character: control of the machines (mostly done by female workers); maintenance and repairs (done by highly specialised craftsmen); transport of materials (done by unskilled male workers). The manufacturing process can be characterised as a 'one-way road' where all the various steps are extremely interdependent. It starts with the delivery of tobacco and ends with the dispatch of packed-up cigarettes. Horizontal co-operation is therefore a technical demand: it is the collective task of all employees to ensure the continuous work of all machines and to prevent interruptions in the manufacturing process. Co-operation among and within departments is necessary. 'Profit centres', for example, would be impossible and senseless.

A measureable judgement of individual performance in the sense of an output rate is meaningless; a judgement can - at best - be passed 
indirectly; performance is measured in terms of the grade of functional incorporation in the technical and co-operative social process. In addition to technical qualifications, 'social' qualifications of the employees become particularly relevant here; not only formal discipline but also the ability to co-operate, to understand the production process, personal initiative, and dispositional capabilities. In principle, this applies to employees in all positions of the business hierarchy. As an example, the personnel manager stated that the criterion for engagement of a new employee is to the extent of $5^{\mathrm{I}}$ per cent 'that he fits in with us', and only 49 per cent his professional qualifications. Also, it is management's practice to give commendations to the working group, and not to individuals.

Moreover, all technical installations as well as material and products must be dealt with carefully and attentively. The high-level technology, a result of externally grounded constraints for rationalisation, demands from or gives the employees a broad scope of action and disposition. On the other hand, the aforementioned interdependence of the production steps renders the entire process extremely sensitive to active or passive forms of restriction of output. For the firm, this means that this applied technology carries the risk of potential reduction in power and control; the sensitive and expensive machines require a maximal control of the adequate accomplishment of all tasks and, at the same time, of the intensive use of the workforce in order to keep the manufacturing process free from interruptions.

This shows that the firm's actions create, on the one hand, a broader scope for the employees; on the other hand, it is forced to develop a policy of personnel management which ensures that the employees use the technically produced opportunities to bring about the desired productivity.

These demands cannot be accomplished by mere pressure. Instead, the firm tries to integrate its staff socially to guarantee the identification of all employees with the efficiency of 'their' respective department (which is finally identical with the firm's efficiency) by self-motivation, internalised control, and long-term commitment to the firm. High wages, above-average benefits, 'co-operative management', and safety of jobs are supposed to guarantee these aims. Additionally, the interdependence of the workplaces requires 'educational work' within the working groups themselves.

These practices lead to a specific relation to the external labour market. The firm becomes a relatively closed system, with only limited application of market mechanisms. Vacancies are filled as far as possible from the internal labour market, and even the recruitment from outside 
is partly 'internalised', the firm relying more on personal recommendations by the already employed than on formal mechanisms of the external labour market. Firm-specific knowledge and qualifications, acquired on the job, are needed to carry on tasks. Because the costs of this acquisition are borne by the firm, the employment should be maintained as long as possible to pay back the investment. For the employees, the closed character of the firm and the specificity of the acquired qualifications operate in the same direction, because these specific qualifications are of little value on the external labour market. In principle, this also applies to the unskilled workers; besides that, a high degree of unemployment is at present characteristic for this group - a menace that is an additional incentive to furnish adequate working behaviour.

In other words, the firm's intentions to control optimally the manufacturing process are realised under the given conditions by getting a 'well socialised' staff, by avoiding a high rate of personnel fluctuation as well as by the staff's long-term commitment to the firm. These aims, however, become problematic for the firm's policy of personnel management under two aspects. (I) The pressure of permanent rationalisation and minimal feasibility of increased output creates the risk of a 'personnel overhang' (mainly of unskilled workers). (2) As to the older (skilled) workers, there is a growing risk that (in addition to possibly damaged health) their qualifications will become obsolete as a result of technical progress.

In both cases, the firm is interested in reducing the number of employees. Due to the length of usefulness of labour and to the increased risk of diminishing performance, the older employees are the first to be made redundant. The firm's retirement regulation is an instrument that optimally guarantees the desired withdrawal of older employees: in most cases, it produces a shortening of the life working time - above all by the pressure to be forced to choose the earliest possible date of retirement if one wants to claim the regulation's advantages.

The opportunity to work part-time for two years can easily be practised within those groups of employees who are doing unskilled work (such as transportation of materials), or whose workplaces are not directly related to the functioning of the manufacturing process (such as some of the craftsmen who are doing general repair and construction work). For those whose workplaces are directly related to the functioning of the machines (some craftsmen, technical foremen, and the women who operate the machines), some difficulties arise. The change of machine-'generations' occurs about every seven years. This is done gradually, so that old and new 'generations' of machines are running 
at the same time. For older employees, the permanent change means potential obsolescence of their primary qualifications. Due to the orientation to the length of usefulness, the firm is not interested in the retraining of the older employees. Instead, the firm practises a parallel 'running down' of old machines and old employees. This process has a very special timing: it comes to its end when the respective employees reach the age at which they are eligible for the early retirement regulation. Part-time jobs without too much disqualification are hard to get for these employees. The same applies to those on higher levels of the hierarchy - part-time work would mean disqualification for them. For this reason they have no real choice between different modes of retirement, but are forced to leave the firm as soon as possible. For these groups, the age when they can take advantage of the regulation (i.e. $5^{8}$ or $6 \mathrm{I}$ ) thus becomes identical with their real retirement age. As the alternative of 'normal' work after this date is practically never chosen, personnel reduction is ensured.

In order to understand why the firm develops such an extraordinary and expensive instrument for its aims, it is necessary to look at this regulation in relation to the technical-organisational demand for an integrative policy of personnel management. Within the age stratification of the firm's workforce, the older employees stand for the continuity and the 'hereditary' transmission of the firm-specific skills and knowledge. 'Older employees' here refers to time of membership in the firm's workforce, not so much to chronological age. These employees are outstanding 'socialisation authorities', while the older employees in the sense of chronological age stand for increased probability of damaged health and minimised potential length of usefulness. The retirement regulation is responsive to the older employees' preferences. This formal voluntarism and flexibility, and the money 'for nothing' when claiming the regulation's provisions, turns the firm's need for personnel reduction into an attractive incentive.

Consequently, the retirement scheme gives the firm more flexibility in its policies of personnel deployment. At the same time, it corresponds to the employees' lifetime reciprocity expectancy, and their necessary social integration is increased.

\section{Consequences}

The example presented here shows that the organisation of ageing and the establishment of retirement regulations extensively follow the demands of the capitalist organisation of work, and of the specific 
economic and technological conditions. In the case of our firm it becomes obvious, too, that economic rationality is to a high degree tied to the life-world integration of the employees. We postulate that the firm's actions, grounded in economic interest, can be carried through effectively only to the extent that they are 'translated' into valid life-world interpretations of the interactional conditions.

This should not be misinterpreted as a rediscovery of the 'human relations' programme, which treats the attitudes and feelings of employees as unrelated to the technical and social organisation of the manufacturing process. In our case, the necessity to refer to life-world orientations follows from this specific organisation, related to the external conditions of the market (above all, from the erosion of the traditional conception of performance). Ageing in the firm and the treatment of older employees have become a medium of mastering the contradictory orientations for economic behaviour: reduction of personnel, especially of the elderly, and social integration of the personnel, especially by providing job security and lifetime reciprocity.

One can assume that this type of technical and social organisation of the manufacturing process will spread over more and more fields of industrial production. If so, the regulation described above does not simply represent an exceptional case, but can be considered as a model for other firms and branches or even for national regulations. From this point of view, ageing and retirement schemes are becoming relevant for coping with problematic situations on the labour market. Considering the present discussion on working time (in the FRG), we agree with Phillipson's ${ }^{21}$ position:

This economic and technological environment was to shift once more the position of the elderly in the labour market, as it was to change ideologies concerning retirement... In the space of 30 years we have seen a remarkable turn-around in labour policies towards retirement. ... The state is, in fact, expanding the retired population, whilst at the same time attempting to channel expectations into acceptable forms.

This means that analyses of the movement of retirement age limits, and of other features of the retirement regime, must focus on the development of technology and the labour market, its relevance as a primary issue on the public agenda, and the process of coping with it in terms of social policies that are available in a given political system. There are welcome signs of a renewed interest, among sociologists of ageing, in these processes. ${ }^{22}$ Beyond that, we were able to show why the lowering of the retirement age is advantageous to the single enterprise - especially in comparison with other forms of reduction of working time (e.g. daily, weekly, or yearly schedules). By this, we can account for the fact that 
such a model, besides being discussed, has real chances for implementation because it conforms with the economic interests expressed by management. ${ }^{23}$ This is to say that, if we are to understand why some policies (e.g. the lowering of the age limit) are more available than others (e.g. pushing part-time work and providing for sabbaticals), analyses on the national level are not enough. Rather, we have to move to the level of the enterprise, and to examine its strategies of organising the life-course of its workers.

\section{NOTES}

I Riley, M. W. Aging and society. Volume 3: A sociology of age stratification, Russell Sage, New York, 1972.

2 Bengtson, V. L. and Dowd, J.J. Sociological functionalism, exchange theory and life-cycle analysis: a call for more explicit theoretical bridges. International Journal of Aging and Human Development, 12 (1 980), 455-73.

3 This period - usually called 'middle adulthood' - may be a particularly critical period in the ageing process of individuals (cf. M. Kohli, Lebenslauf und Lebensmitte. Kölner Zeitschrift für Soziologie und Sozialpsychologie, 29 ( I 977), 625-656). It is by now widely accepted that the study of ageing should not be restricted to old age proper, but should rather be conceptualised within a life-course framework. However, substantive analyses of ageing before old age are still notably lacking.

4 Some fields of historical research which contribute to our knowledge of this process are already extensively developed (historical demography, history of the family, history of mentalities, etc.); the history of old age, and especially of retirement, has begun only recently (cf. the overview by $\mathrm{C}$. Conrad, Altwerden und Altsein in historischer Perspektive, Zeitschrift für Sozialisationsforschung und Erziehungssoziologie, 2(1982), 73-91). Thus the empirical support for our thesis is still limited. For a sociological interpretation of the chronologisation process see M. Kohli, Social organization and subjective construction of the life-course. Paper prepared for the International Conference on Life-Course Research on Human Development, Berlin, I6-2 I September 1982.

5 Kohli, M., op. cit. I982.

6 Habermas, J. Theorie des kommunikativen Handelns. 2 volumes. Suhrkamp, Frankfurt/M., r 981 .

7 Thomae, H. and Lehr, U. Berufliche Leistungsfähigkeit im mitlleren und höheren Erwachsenenalter. Schwartz, Göttingen, r973.

8 Dohse, K. et al. (eds.). Allere Arbeitnehmer zwischen Unternehmensinteressen und Sozialpolitik. Campus, Frankfurt/M., 1982.

9 Lehr, U. and Thomae, H. Soziale Dienste für alte Menschen. Studie zur Kommunalpolitik. In: Konrad-Adenauer-Stiftung (ed.), Schriftenreihe des Instituts für Kommunalwissenschaften, Volume 7, Bonn, 1976, Pohl, H.-J. Ältere ArbeitnehmerUrsachen und Folgen beruficher Abwertung. Campus, Frankfurt/M., I 976. Hohmeier, J. and Pohl, H.-J. (cds.). Alter als Stigma - oder : wie man alt gemacht wird. Suhrkamp, Frankfurt/M., 1978.

Io Schmidt, H. Der ältere Arbeitnehmer im technischen Wandel. Hanser, München, I 977.

I I Rosenow, J. and Gehrmann, M. Altern im Betrieb-Handlungsrelevanz und Altersselektivität von Typisierungsprozessen im betrieblichen Arbeitskräfteeinsatz. Arbeitsbericht Nr. 5 des Projekts Arbeit und Altern. Berlin, 1982 (mimeo). 
12 Bäcker, G. Der ältere Arbeitnehmer auf Arbeitsplatz und Arbeitsmarkt. Ein Beitrag zur Diskussion über Entstehung und Verfestigung von "Problemgruppen". Sozialer Fortschritt, 28 (1979), 64-67, 1 I 2-1 1 8, I 35-1 37.

I3 Habermas, J., Vorbereitende Bemerkungen zu einer Theorie der kommunikativen Kompetenz. In J. Habermas and N. Luhmann, Theorie der Gesellschaft oder Sozialtechnologie - Was leistet die Systemforschung? Suhrkamp, Frankfurt/M., I 97 I.

14 Altmann, N. et al., Betrieb-Technik-Arbeit. Elemente einer soziologischen Analytik technisch-organisatorischer Veränderungen. Campus, Frankfurt/M., I 978.

I5 Rosenow, J. Die soziale Organisation von Prozessen des Alterns im Betrieb. Ủberlegungen zum Sozialisations-potential betrieblicher Probleme in mittleren Erwachsenenalter für den psycho-sozialen Prozess des Alterns In K. Dohse et al. (eds.), op. cit. 1982 .

I6 Dohse, K. et al., Probleme einer Beschränkung gewerkschafllicher Bestandsschutzpolitik auf die Absicherung älterer Arbeitnehmer - Zum Verhältnis von Bestandsschutz un personalpolitischer Flexibilitat. Wissenschaftszentrum, Berlin, 1978.

I 7 The study is supported by the Volkswagen Foundation. It began in June I98o and will end in February 1983 . We are grateful to our colleagues Manfred Gehrmann and Nicola Hawkins for their contributions.

I 8 For a detailed analysis of. Wolf, J., "Gleitender Ruhestand" als betriebliche Strategie: die Relevanz des Lebensalters und die Bedeutung der Ausgliederung von Arbeitnehmern im Rahmen der industriellen Arbeitsorganisation. Eine Fallanalyse am Beispiel der "Sonderregelung für ältere Arbeitnehmer" der Cigarettenindustrie.' Berlin I981 (Diplomarbeit).

19 Henniges, H. von. Gewünschte Arbeitszerit vollbeschäftigter Arbeitnehmer. Sonderauswertung aus der Voruntersuchung des BiBB/IAB-Projekts 'Qualifikationsvertwertung und berufliche Mobilität.' Mitteilungen aus der Arbeitsmarkt- und Berufsforschung, 12 (1979), 270-275.

20 Zander, E. Die Suche nach der sozialen Losung. Manager Magazin, 10 (1978), I3I-I34.

21 Phillipson, C., The state, the economy and retirement. Paper presented to the Round Table: Old age and public social policies, Paris, 8-1o July 1981.

22 Cf. the contributions to the ISA symposium 'Old age...; op. cit.

23 Cf. the survey of the German IFO Institute; while refusing most of the proposals to reduce working time, the majority of German managements recommended an earlier retirement age limit (cf. Bundesanstalt für Arbeit: Überlegungen II zu einer vorausschauenden Arbeitsmarktpolitik, Nürnberg, 1978). 